\title{
A Large-Scale Population-Based Study of the Association of Vitamin D Receptor Gene Polymorphisms with Bone Mineral Density*
}

\author{
ANDRÉ G. UITTERLINDEN, ${ }^{1}$ HUIBERT A.P. POLS,${ }^{1,2}$ HUIBERT BURGER, ${ }^{2}$ QIUJU HUANG, ${ }^{2}$ \\ PAUL L.A. VAN DAELE, ${ }^{1}$ CORNELIA M. VAN DUIJN, ${ }^{2}$ ALBERT HOFMAN ${ }^{2}{ }^{2}$ JAN C. BIRKENHÄGER, \\ and JOHANNES P.T.M. VAN LEEUWEN ${ }^{1}$
}

\begin{abstract}
Conflicting results have been reported on the association between restriction fragment length polymorphisms (RFLPs) at the vitamin D receptor (VDR) gene locus (i.e., for BsmI, ApaI, and TaqI) and bone mineral density (BMD). We analyzed this association in a large population-based sample $(n=1782)$ of men and women aged 55-80 years using a novel direct haplotyping polymerase chain reaction (PCR) test to monitor the three polymorphic sites simultaneously. The direct haplotyping test we developed demonstrated a larger degree of genetic polymorphism at the VDR gene locus than described until now. None of the individual RFLPs were associated with BMD at the proximal femur. By analyzing allele dose effects, we identified a VDR haplotype allele weakly associated with low BMD. This allele, as one representative of the group of $b$ alleles, is different from the $B s m I$ allele previously reported by other groups to be associated with low BMD. This suggests allelic heterogeneity at the VDR locus in relation to BMD. Our results indicate at most a small effect of the VDR genotype on BMD in this elderly population. Since anonymous polymorphisms were analyzed, alternative explanations for our results include linkage to another nearby bone-metabolism related gene. (J Bone Miner Res 1996;11:1241-1248)
\end{abstract}

\section{INTRODUCTION}

$\mathrm{O}$ STEOPOROSIS is characterized by low bone mineral density (BMD) and microarchitectural deterioration of bone tissue leading to increased bone fragility and susceptibility to fracture. Up to $75 \%$ of variation in BMD has been suggested to be determined by genetic factors. ${ }^{(1,2)}$ Recent studies have demonstrated a genetic association between the vitamin D receptor (VDR) gene locus and BMD in Caucasian, ${ }^{(3-6)}$ Japanese, ${ }^{(7)}$ and black women. ${ }^{(8)}$ Other

*Parts of this work were presented as an abstract at the XXIVth European Symposium on Calcified Tissues on May 27-30, 1995, in Aarhus, Denmark, and at the 17th annual meeting of the American Society for Bone and Mineral Research on September 9-13, 1995, in Baltimore, Maryland, U.S.A. studies of similar size, however, could not corroborate these findings. ${ }^{(9-12)}$ There may be several explanations for the discrepancy between these studies. ${ }^{(13)}$ First, the sample size and consequently the statistical power of the previous studies was limited. Second, there may have been bias, e.g., due to population admixture in studies, suggesting an association. Third, linkage disequilibrium may exist, e.g., the VDR gene locus itself may not be causally related to BMD but is linked to a neighboring bone-metabolism related gene. Because recombination between the VDR gene and the putative bone-metabolism related gene may occur at each meiosis, linkage disequilibrium may be found in some populations but not in others. Fourth, there may be allelic heterogeneity, i.e., the VDR gene may be implicated in BMD, but different gene variants are associated with BMD in different populations. The lack of association can then be

'Department of Internal Medicine III, Erasmus University Medical School, Rotterdam, The Netherlands.

${ }^{2}$ Department of Epidemiology \& Biostatistics, Erasmus University Medical School, Rotterdam, The Netherlands. 
explained by the fact that a given polymorphism is not testing for the VDR gene variant in a particular population and by using less informative genetic markers.

To address these problems, we have analyzed in a large population-based sample from the Rotterdam Study ${ }^{(14)}$ the association between VDR genotype and BMD of the proximal femur. The power of an association study can be increased when informative, multiallelic markers are used. The marker mostly analyzed so far in relation to BMD is an anonymous intronic restriction fragment length polymorphism for Bsm I between exons 7 and 8 of the VDR gene. ${ }^{(3)}$ This marker discriminates only two alleles combining to three genotypes. For our study, we developed a genetically more informative direct haplotyping PCR test to monitor three clustered anonymous restriction site polymorphisms at the VDR gene locus simultaneously. Preliminary results ${ }^{(15.10)}$ using this novel genotyping method suggested a considerable effect of VDR genotype on BMD in our population. To increase further the statistical power of our study, we expanded the number of individuals to include 880 men and 902 women.

\section{MATERIALS AND METHODS}

\section{Subjects}

The Rotterdam Study is a prospective population-based cohort study of determinants and prognosis of chronic diseases in the elderly. ${ }^{(14)}$ Eligible for the study were all inhabitants aged 55 years or over of the district of Ommoord in Rotterdam, The Netherlands. A total of 10,275 persons, of whom $9161(89 \%)$ were living independently, were invited for the study. In the independently living population, the overall response rate was $77 \%$ for the home interview and $71 \%$ for the examination in the research centre. Written informed consent was obtained from each participant. The Rotterdam Study has been approved by the Medical Ethics Committee of Erasmus University Medical School. The analysis of the association between VDR genotype and BMD was performed in a sample from the Rotterdam Study. From all 5931 independently living participants with bone density measurements, 1453 subjects were excluded according to the following criteria: older than 80 years, use of a walking aid, known diabetes, or use of cytostatics, thyroid hormone, or diuretics. From the 4478 remaining subjects, an age-stratified random sample of $1000 \mathrm{men}$ and 1000 women was drawn with balanced numbers $(200)$ in 5 -year age categories. VDR genotyping data and bone density measurements of 880 men and 902 women were available for analysis.

\section{Bone mineral density measurement}

BMD (in $\mathrm{g} / \mathrm{cm}^{2}$ ) at the femoral neck and Ward's triangle was determined by dual-energy X-ray absorptiometry (DXA; Lunar Corporation, Madison, WI, U.S.A.) as described previously. ${ }^{(17)}$ Because of possible bias due to osteoarthritis, BMD measurements of the lumbar spine were not included. ${ }^{(17)}$

\section{Genotyping procedure}

Three anonymous polymorphic restriction enzyme recognition sites at the $3^{\prime}$ end of the VDR gene, i.e., BsmI, Apal, and TaqI ${ }^{\left(18.1^{19)}\right.}$ were assessed individually and in relation to each other by a direct haplotyping polymerase chain reaction (PCR) procedure which we developed. The direct haplotyping procedure is schematically depicted in Fig. la. Onc hundred nanograms (ng) of genomic DNA was used for PCR amplification in a reaction mixture containing $50 \mathrm{mM} \mathrm{KCl}, 10 \mathrm{mM}$ Tris-HCl (pH 8.3), $1.5 \mathrm{mM} \mathrm{MgCl}_{2}, 0.2 \mathrm{mM}$ dNTP, $150 \mathrm{ng}$ of each primer, and $0.2 \mathrm{U}$ of Super Taq polymerase (HT Biotechnology, Cambridge, U.K.). Primer VDR1 = 5'-CAACCAA GACTACAAGTACCGCGTCAGTGA-3'; primer VDR4 = 5'-GCAACTCCTCATGGCTGAGGTCTC-3' ${ }^{\prime(3,4)}$ The reactions were performed in a DNA thermocycler (model 480, Perkin Elmer, Norwalk, CT, U.S.A.) and consisted of 94, 60 , and $72^{\circ} \mathrm{C}$ for 1 minute each, for 25 cycles. Twenty microliters $(\mu \mathrm{l})$ of the PCR products were digested in a single tube with $5 \mathrm{U}$ each of $B \mathrm{smI}, A p a \mathrm{I}$, and TaqI simultaneously, and 2.5 $\mu \mathrm{l}$ of a $10 \times$ buffer (containing $150 \mathrm{mM}$ Tris- $\mathrm{HCl}, \mathrm{pH} 7.5,250$ $\mathrm{mM} \mathrm{NaCl}$, and $35 \mathrm{mM} \mathrm{MgCl}$ ) by subsequently incubating for 30 minutes at $31^{\circ} \mathrm{C}$ followed by 30 minutes at $65^{\circ} \mathrm{C}$.

Digestion products were analyzed on a $1.4 \%$ agarose gel run in $0.5 \times$ TBE $(1 \times \mathrm{TBE}=89 \mathrm{mM}$ Tris, $89 \mathrm{mM}$ boric acid, $2 \mathrm{mM} \mathrm{Na}_{2}$ EDTA) for 250 volt hours (Vh). Separation patterns were documented by Polaroid photography under UV-illumination $(302 \mathrm{~nm})$. The alleles were named similarly as previously described for alleles defined by individual RFLPs ${ }^{(18,19)}$ : in genotypes such as BAt-baT, capital letters denote absence and lowercase letters the presence of the site for the restriction enzymes $B s m \mathrm{I}(\mathrm{B} / \mathrm{b}), \operatorname{Apal}(\mathrm{A} / \mathrm{a})$, and TaqI (T/t) on each of the alleles.

To monitor complete digestion of the PCR products for each of the restriction enzymes used, the fragments indicated with $b$, aT, and $t$ in Fig. $1 \mathrm{~b}$ are used. The $b$ fragment of 650 bp will only appear for those haplotypes carrying a BsmI recognition site (Fig. 1a), the t fragment of $202 \mathrm{bp}$ will appear only for those haplotypes carrying a TaqI recognition site, while the aT fragment will only appear for those haplotypes carrying an ApaI recognition site but no TaqI recognition site. A technical problem that we initially encountered in this genotyping procedure was the occurrence of heteroduplex molecules (in which the + and - strands of heterologous alleles are base-pairing) which cannot be digested. By controlling the yield of the PCR amplification (e.g., by performing less cycles), this problem was effectively eliminated. To assess correspondence between the novel haplotyping procedure and the genotyping procedures for determining single restriction sites, ${ }^{(3.4)}$ we analyzed 200 randomly selected DNA samples by both procedures.

\section{Statistical analysis}

The BMD data are presented as means \pm standard deviation (SD) or with $95 \%$ confidence intervals $(95 \% \mathrm{CI})$. Rare genotypes ( $n \leq 10$ in either men or women) were excluded from the analysis. Mean BMD was compared for different genotypes by analysis of covariance (ANCOVA). Allele dose was defined as the number of copies of a 


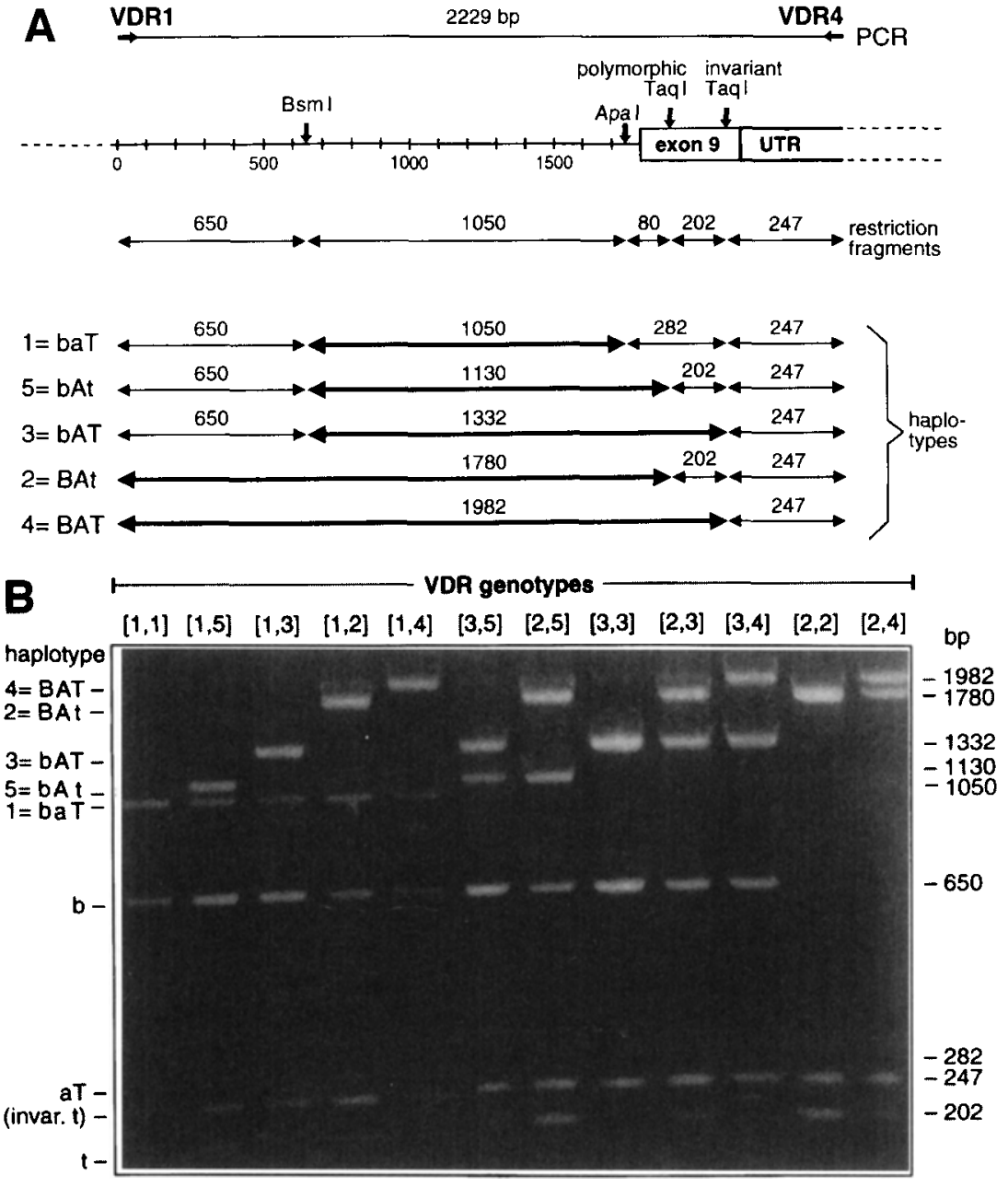

FIG. 1. (a) Schematic presentation of the direct haplotyping PCR procedure for analysis of the three polymorphisms in the 3 end of the VDR locus. UTR $=$ untranslated region. (b) Gel electrophoretic separation pattern of restriction fragments obtained after the PCR procedure shown in (a) from 12 individuals with different VDR genotypes. The haplotype notation on the left of the figure corresponds with the one shown in (a) and indicates the specific restriction fragments characteristic for each haplotype. b, aT, and t indicate fragments characteristic for the presence of an individual $(b, t)$ or a combination of two restriction sites (aT). invar. $t$ denotes a fragment always observed as a result of the presence of an invariant TaqI site in exon 9 (a). Numbers above the lanes refer to genotypes described in Table 4. particular allele in the genotype. The relation between allele dose and BMD was quantified by linear regression analysis for the BsmI alleles B and $\mathrm{b}$ and the more common haplotype alleles (i.e., alleles 1, 2, and 3). Since age and body mass index (BMI) are known determinants of bone density, all analyses were carried out while adjusting for age and BMI.

\section{RESULTS}

General characteristics of the population are presented in Table 1. Allele and genotype frequencies for the Bsm I restriction fragment length polymorphism (RFLP) are shown in Table 2. We first analyzed the association between BMD and VDR genotype defined by the BsmI restriction site polymorphism (Table 3 ). Although in women the BB genotype had a slightly higher BMD, no significant differences were observed between genotype groups in either men or women for the femoral neck nor for the Ward's triangle. Allele copy number of the $\mathrm{B}$ or $\mathrm{b}$ allele was not significantly related to BMD. No differences in mean BMD levels for different $A p a \mathrm{I}$ and TaqI genotypes were observed (data not shown).
Table 1. Characteristics of thl: Population

\begin{tabular}{|c|c|c|}
\hline $\begin{array}{c}\text { Base line } \\
\text { characteristic }\end{array}$ & Men & Women \\
\hline Number & 880 & 902 \\
\hline Age (years) & $67.5 \pm 7.1$ & $67.5 \pm 7.0$ \\
\hline $\mathrm{BMI}\left(\mathrm{kg} / \mathrm{m}^{2}\right)$ & $25.5 \pm 2.9$ & $26.2 \pm 3.7$ \\
\hline \multicolumn{3}{|l|}{$\operatorname{BMD}\left(\mathrm{g} / \mathrm{cm}^{2}\right)$} \\
\hline Femoral neck & $0.870 \pm 0.130$ & $0.803 \pm 0.129$ \\
\hline Ward's triangle & $0.720 \pm 0.146$ & $0.667 \pm 0.140$ \\
\hline
\end{tabular}

Values are means $\pm \mathrm{SD}$.

Comparison of genotyping results obtained by analysis of single RFLPs and haplotypes showed no discrepancies. When the total population was analyzed using the direct haplotyping procedure, we identified five different alleles at the VDR gene locus coded 1 to 5 by decreasing frequency. The haplotypes combined to 12 different genotypes (Fig. 1b), of which the frequencies are presented in Table 4. There were no significant differences in allele frequencies between men and women. At the haplotype level there is at $99 \%$ concordance between $\mathrm{b}$ and $\mathrm{T}$ (and $\mathrm{B}$ and $\mathrm{t}$ ). No 
Table 2. BsmI Allele and Genotype Distribution

\begin{tabular}{llll}
\hline & $\begin{array}{c}\text { Men } \\
\mathrm{n}(\%)\end{array}$ & $\begin{array}{c}\text { Women } \\
\mathrm{n}(\%)\end{array}$ & $\begin{array}{c}\text { All } \\
\mathrm{n}(\%)\end{array}$ \\
\hline $\begin{array}{l}\text { Allele }^{*} \\
\mathrm{~b}\end{array}$ & $1034(58.7)$ & $1064(59.0)$ & $2098(58.9)$ \\
B & $726(41.3)$ & $740(41.0)$ & $1466(41.1)$ \\
$\quad$ Total & $1760(100)$ & $1804(100)$ & $3564(100)$ \\
$\begin{array}{l}\text { Genotype } \\
\text { Bb }\end{array}$ & $396(45.0)$ & $414(45.9)$ & $810(45.5)$ \\
bb & $319(36.3)$ & $325(36.0)$ & $644(36.1)$ \\
BB & $165(18.7)$ & $163(18.1)$ & $328(18.4)$ \\
Total & $880(100)$ & $902(100)$ & $1782(100)$ \\
\hline
\end{tabular}

${ }^{*} n=$ number of chromosomes; ranking is according to frequency.

${ }^{+} n=$ number of individuals; ranking is according to frequency.

significant departures from Hardy-Weinberg equilibrium were observed for each of the three RFLPs separately nor for the haplotypes. Heterozygosity was $45.5 \%$ for the Bsm I RFLP and $56.7 \%$ for VDR alleles defined by haplotypes.

Mean BMD values at the proximal femur of women and men in relation to VDR genotypes, as assessed by the direct haplotyping procedure, are shown in Table 5. Differences in mean BMD at the femoral neck and the Ward's triangle could be observed among VDR genotypes in men and women, although none reached significance. In men the $[1,3],[2,3]$, and $[3,3]$ had a BMD lower than the population average, whereas in women the $[2,2]$ had a slightly higher $\mathrm{BMD}$ and the $[3,3]$ a lower BMD. The difference in BMD between extreme genotypes in women was $7.3 \%$ (corresponding to $0.5 \mathrm{SD}$ ) of the highest BMD at the femoral neck and $9.7 \%$ (0.5 SD) at the Ward's triangle, while in men this was $4.5 \%(0.3 \mathrm{SD})$ and $4.7 \%(0.2 \mathrm{SD})$, respectively. The VDR haplotype allele dose effect is shown in Table 6; the BMD at the femoral neck decreased by $0.014 \mathrm{~g} / \mathrm{cm}^{2}$ per copy for allele $3(=\mathrm{bAT})$. This allele dose effect was significant in the total population $(p=0.04)$, most notably in men $(p=0.06)$, while similar but not significant in women $(p=0.29)$. A similar but nonsignificant allele dose effect of allele 3 on BMD was observed at the Ward's triangle. When the analysis of allele dose effect was agestratified (above and below the median age of 67 years), we observed for allele 3 a stronger dose effect in women 55-67 years of age $\left(-0.019 \mathrm{~g} / \mathrm{cm}^{2}[95 \% \mathrm{CI},-0.044-0.007 ; p=\right.$ $0.15])$ compared with women $67-80$ years of age $(-0.002$ $\mathrm{g} / \mathrm{cm}^{2}$ [95\% CI, $\left.-0.026-0.023 ; p=0.91\right]$ ). For men, no relation of allele dose with age was found.

Comparison of allele frequencies in the lowest and highest BMD quintile of the population (cut off value for the lowest quintile is $0.764 \mathrm{~g} / \mathrm{cm}^{2}$ for men and $0.698 \mathrm{~g} / \mathrm{cm}^{2}$ for women, and in the highest quintile $0.987 \mathrm{~g} / \mathrm{cm}^{2}$ for men and $0.913 \mathrm{~g} / \mathrm{cm}^{2}$ for women) revealed no differences for alleles 1 and 2 . Allele 3 had a higher frequency in the lowest quintile (13.4\% for men and $13.1 \%$ for women) compared with the frequency in the highest quintile $(10.7 \%$ for men and $8.9 \%$ for women; $p=0.12$ for men and $p<0.01$ for women).

\section{DISCUSSION}

In a large ethnically homogeneous population-based sample, we studied the association between BMD measured at the proximal femur and VDR genotype. While we did not detect an association between individual RFLPs and BMD, the results suggest a weak association between BMD and VDR genotype as measured by direct haplotyping, with a similar trend in men and women. In women, the differences in BMD between extreme genotypes (i.e., the rare [3,3] and the more common [2,2] genotype) amounted up to $0.5 \mathrm{SD}$ both at the femoral neck and at the Ward's triangle, while in men this difference was up to $0.3 \mathrm{SD}$. We previously reported larger differences in a smaller number $(n=800)$ of individuals from this population. ${ }^{(15,16)}$ This imprecision in estimating mean BMD levels per genotype group probably is a result of low numbers per group. In the latter case, the likelihood of overestimating the magnitude of an association is considerable. An increase in the number of genotypes (because of increased genetic resolution) requires a concommittant increase in sample size to achieve stable and precise point estimates. Because the numbers of individuals per genotype group have now increased considerably, we consider the current estimates to be more reliable and conclude that the VDR genotype has a small effect on BMD in this elderly population.

The increased genetic resolution obtained by direct haplotyping of all three polymorphic sites allowed five different allelic variants of the VDR gene to be discriminated, of which three are common. A genetically meaningful and efficient way to study genotype effects on BMD is to analyze allele dose effects. When the trend among genotypes was analyzed with respect to allele dose, we found the 3 allele (i.e., bAT) to be associated with low BMD. In keeping with these results, we found the allele 3 to be overrepresented in the lowest BMD quintile. In men, the allele dose effect was additive, with the homozygous $[3,3]$ having a lower BMD than the heterozygous $[1,3]$ and $[2,3]$, which in turn have a BMD lower than that of individuals not carrying allele 3. In women, the heterozygote effect is blurred, perhaps by the influence of determinants of BMD other than VDR, e.g., estrogen status.

When the analysis is limited to only the $B s m I$ site, the five existing haplotype alleles are combined to two alleles (B and b). In our study, no allele dose effect of Bsml alleles could be observed. This is substantiated by the fact that the $[1,1]$ genotype has a high mean BMD level at the femoral neck in women and the $[3,3]$ the lowest mean $\mathrm{BMD}$, while both are homozygous bb. We also observed similar trends both in men and women using the haplotype analysis, while no effect on BMD was seen with the individual polymorphisms. Therefore, low genetic resolution can obscure an association between the BMD level and VDR genotypes in studies using individual restriction enzyme recognition site polymorphisms. ${ }^{(9-12)}$

We observed frequencies of the two alleles for the BsmI polymorphism that are almost identical to those of other studies in Caucasians. ${ }^{(3-6,9-12)}$ Surprisingly, however, the particular VDR haplotype allele we found associated with 
Table 3. Mean BMD at the Proximal Femur by Bsm Genotype

\begin{tabular}{lccccc}
\hline Genotype & $\mathrm{n}$ & Femoral neck & $\mathrm{p}^{\dagger}$ & Ward's triangle* & $\mathrm{p}^{\dagger}$ \\
\hline Men & & & & & \\
BB & 165 & $0.876(0.857-0.894)$ & - & $0.721(0.701-0.743)$ & 0.70 \\
Bb & 396 & $0.870(0.858-0.881)$ & 0.59 & $0.719(0.705-0.732)$ & 0.88 \\
bb & 319 & $0.869(0.855-0.882)$ & 0.56 & $0.720(0.705-0.735)$ & \\
Total & 880 & & & & \\
Women & 163 & $0.817(0.796-0.832)$ & - & $0.684(0.661-0.700)$ & 0.09 \\
BB & 414 & $0.798(0.787-0.810)$ & 0.16 & $0.659(0.648-0.672)$ & 0.37 \\
Bb & 325 & $0.802(0.790-0.815)$ & 0.31 & $0.668(0.655-0.683)$ & \\
bb & 902 & & & & \\
Total & & & &
\end{tabular}

${ }^{*} \mathrm{BMD}$ is age- and BMI-adjusted; the $95 \% \mathrm{CI}$ is presented in brackets.

${ }^{+}$Significance of differences versus BB.

Table, 4. VDR Haplotype and Genotype Freoulencies*

\begin{tabular}{lcccc}
\hline & Code & $\begin{array}{c}\text { Men } \\
(\%)\end{array}$ & $\begin{array}{c}\text { Women } \\
(\%)\end{array}$ & $\begin{array}{c}\text { All } \\
(\%)\end{array}$ \\
\hline $\begin{array}{l}\text { Haplotypes } \\
\text { baT }\end{array}$ & 1 & & & \\
BAt & 2 & $711(40.4)$ & $730(40.5)$ & $1741(47.7)$ \\
bAT & 3 & $197(11.1)$ & $191(10.5)$ & $388(10.9)$ \\
BAT & 4 & $15(0.9)$ & $10(0.6)$ & $25(0.7)$ \\
bAt & 5 & $5(0.3)$ & $4(0.2)$ & $9(0.3)$ \\
Total & & $1760(100)$ & $1804(100)$ & $3564(100)$ \\
Genotypes & & & & \\
baT-BAt & {$[1,2]$} & $308(35)$ & $331(37)$ & $639(36)$ \\
baT-baT & {$[1,1]$} & $212(24)$ & $223(25)$ & $435(24)$ \\
BAt-BAt & {$[2,2]$} & $159(18)$ & $155(17)$ & $314(18)$ \\
baT-bAT & {$[1,3]$} & $93(11)$ & $88(9.7)$ & $183(10)$ \\
BAt-bAT & {$[2,3]$} & $76(8.5)$ & $79(8.6)$ & $155(8.6)$ \\
bAT-bAT & {$[3,3]$} & $12(1.3)$ & $12(1.2)$ & $24(1.3)$ \\
BAt-BAT & {$[2,4]$} & $6(0.7)$ & $8(0.9)$ & $14(0.8)$ \\
baT-BAT & {$[1,4]$} & $6(0.7)$ & $2(0.2)$ & $8(0.5)$ \\
BAt-bAt & {$[2,5]$} & $3(0.3)$ & $2(0.2)$ & $5(0.3)$ \\
bAT-BAT & {$[3,4]$} & $3(0.3)$ & - & $3(0.2)$ \\
baT-bAt & {$[1,5]$} & $1(0.1)$ & $2(0.2)$ & $3(0.2)$ \\
bAT-bAt & {$[3,5]$} & $1(0.1)$ & - & $1(0.1)$ \\
Total & & $880(100)$ & $902(100)$ & $1782(100)$ \\
\hline
\end{tabular}

* Ranking is according to frequency.

${ }^{\dagger} n=$ number of chromosomes.

${ }^{\ddagger} n=$ number of individuals.

low BMD values is different from the one reported earlier. According to previous studies, ${ }^{(3-8)}$ the $b$ allele was associated with a high BMD level and the $B$ allele with a low BMD level. In contrast, we find the bAT haplotype allele (as one representative of the group of $b$ alleles) to be associated with low BMD. In this respect, it should be noted that a study in Scotland has recently also demonstrated an association of the b allele with low BMD. ${ }^{(20)}$ Our results together with those of others indicate that there is either allelic heterogeneity at the VDR locus among different populations or linkage disequilibrium with another bone metabolism-related gene. In the latter case, the difference in the direction of the genetic effect (i.e., which allele is associated with either low or high BMD) can be explained by a recombination which has occurred between the VDR gene and the putative bone metabolism-related gene in our study population. Alternatively, in the case of allelic heterogeneity, it is expected that differences in biological effect and direction of the genetic effect might be accompanied by differences in haplotype distributions among different populations. Arguing against allelic heterogeneity in this respect is the fact that haplotype frequencies in a Japanese 
Table 5. Mean BMD at the Proximal Femur by VDR Haplotype Genotypes*

\begin{tabular}{|c|c|c|c|c|c|}
\hline Genotype & $\mathrm{n}$ & Femoral neck & $\mathrm{p}^{\dagger}$ & Ward's triangle & $\mathrm{p}^{\dagger}$ \\
\hline \multicolumn{6}{|l|}{ Men } \\
\hline$[2,2]$ & 159 & $0.876(0.857-0.894)$ & - & $0.722(0.700-0.743)$ & - \\
\hline$[1,1]$ & 212 & $0.877(0.860-0.893)$ & 0.94 & $0.728(0.709-0.746)$ & 0.69 \\
\hline$[1,2]$ & 308 & $0.871(0.858-0.885)$ & 0.72 & $0.720(0.705-0.736)$ & 0.91 \\
\hline$[1,3]$ & 93 & $0.855(0.830-0.880)$ & 0.19 & $0.708(0.680-0.736)$ & 0.44 \\
\hline$[2,3]$ & 76 & $0.858(0.831-0.886)$ & 0.31 & $0.708(0.676-0.739)$ & 0.46 \\
\hline$[3,3]$ & 12 & $0.837(0.769-0.906)$ & 0.30 & $0.688(0.610-0.766)$ & 0.41 \\
\hline Rare & 20 & not given & & not given & \\
\hline Total & 880 & & & & \\
\hline \multicolumn{6}{|l|}{ Women } \\
\hline$[2,2]$ & 155 & $0.813(0.795-0.832)$ & - & $0.679(0.659-0.699)$ & - \\
\hline$[1,1]$ & 223 & $0.805(0.789-0.820)$ & 0.47 & $0.672(0.655-0.688)$ & 0.56 \\
\hline$[1,2]$ & 331 & $0.800(0.787-0.813)$ & 0.25 & $0.660(0.646-0.674)$ & 0.12 \\
\hline$[1,3]$ & 88 & $0.803(0.779-0.828)$ & 0.52 & $0.670(0.643-0.696)$ & 0.57 \\
\hline$[2,3]$ & 79 & $0.797(0.771-0.823)$ & 0.31 & $0.664(0.636-0.692)$ & 0.37 \\
\hline$[3,3]$ & 12 & $0.754(0.688-0.821)$ & 0.10 & $0.613(0.541-0.685)$ & 0.08 \\
\hline Rare & 14 & not given & & not given & \\
\hline Total & 902 & & & & \\
\hline
\end{tabular}

* Genotypes are ranked according to mean BMD at the femoral neck; rare genotypes have $n \leq 10$ in either men or women; BMD is age- and $\mathrm{BMI}$-adjusted; the $95 \% \mathrm{CI}$ is presented in brackets.

${ }^{\dagger}$ Significance of differences versus $[2,2]$.

Table 6. Regression of BMD at the Proximal Femur on VDR Allele Dose*

\begin{tabular}{lcccccc}
\hline VDR allele & Men & $\mathrm{p}$ & Women & $\mathrm{p}$ & All & $\mathrm{p}$ \\
\hline Femoral neck & & & & & & \\
$\quad$ & $0.004(-0.007-0.015)$ & 0.49 & $-0.001(-0.012-0.011)$ & 0.87 & $0.001(-0.007-0.009)$ & 0.87 \\
2 & $0.003(-0.008-0.014)$ & 0.62 & $0.005(-0.006-0.016)$ & 0.41 & $0.005(-0.004-0.014)$ & 0.27 \\
3 & $-0.018(-0.036-0.0003)$ & 0.06 & $-0.010(-0.027-0.007)$ & 0.29 & $-0.014(-0.027--0.001)$ & 0.04 \\
Ward's triangle & & & & & & \\
1 & $0.006(-0.007-0.019)$ & 0.37 & $0.0001(-0.015-0.012)$ & 0.99 & $0.002(-0.007-0.011)$ & 0.64 \\
2 & $0.001(-0.012-0.013)$ & 0.98 & $0.003(-0.009-0.015)$ & 0.64 & $0.003(-0.007-0.012)$ & 0.58 \\
3 & $-0.016(-0.036-0.005)$ & 0.13 & $-0.008(-0.027-0.007)$ & 0.44 & $-0.012(-0.026-0.002)$ & 0.10 \\
\hline
\end{tabular}

* Presented is the regression coefficient: the increment or decrement in BMD per VDR allele copy (in brackets is the 95\% CI).

population $^{(21)}$ and an Australian population, ${ }^{(18)}$ although inferred and not determined directly, are very different, but they show the same VDR allele being associated with high BMD. In addition, haplotype frequencies in the Australian population and our population are similar, but different VDR alleles are associated with low BMD. The direction of a genetic effect, however, can also be influenced by geneenvironment interactions. Allelic heterogeneity could thus be explained as different alleles having the same effect in different populations due to differences in environment. Environmental influences such as Calcium (Ca) intake are known to differ widely between populations ${ }^{(22)}$ and have been shown to contribute to the genetic effect of VDR genotype on $\mathrm{BMD}^{(5)}$ and on rates of bone loss. ${ }^{(23)}$ However, in a preliminary analysis of dietary $\mathrm{Ca}$ intake in relation to BMD and VDR genotype in our population, which has a relatively high $\mathrm{Ca}$ intake (mean is 1139 and 1093 $\mathrm{mg} /$ day in men and women, respectively), we observed that the small effect of dietary $\mathrm{Ca}$ intake on BMD was not strongly VDR genotype-dependent (data not shown). An analysis of the relationship between the VDR genotype, $\mathrm{Ca}$ intake, BMD, and rates of loss is now under way.

In the absence of knowledge on functional sequence variations in the VDR gene in linkage with the three polymorphisms described so far, neither allelic heterogeneity nor linkage disequilibrium with another bone metabolismrelated gene can be excluded as an explanation for the different direction and magnitude of the genetic effect of VDR genotype on BMD between different studies. In this respect, a more comprehensive analysis of sequence variation in functionally relevant parts of the VDR locus but also in its direct chromosomal vicinity will help to make a distinction. It should be noted that other examples of one allele having different genetic effects are known to occur. For example, in the case of the association between ApoE alleles and early onset Alzheimers disease (EOAD), some 
studies showed a protective effect of the E2 allele while others demonstrated an increased risk of EOAD for ApoE2 carriers. ${ }^{(24)}$ Also in this case, possible explanations for the opposite genetic effect are along the lines described above.

Finally, differences between VDR genotypes in BMD levels could reflect differences in peak bone mass as obtained in young adulthood and/or be due to differences in age-related bone loss. Preliminary follow-up data from our population (mean follow-up time 2.4 years) indicate that a high $\mathrm{BMD}$ is not due to a lower rate of bone loss (data not shown). This at least suggests that subjects with VDR genotypes characterized by a low BMD level are apparently not fast bone losers. In this respect, it should be noted that in an elderly population the VDR genotype effect on BMD can be attenuated by other determinants of BMD such as life-style factors, including diet and mobility. A role of VDR genotype in determining peak bone mass can therefore not be excluded.

In conclusion, we found a weak association between VDR genotype and BMD. The increased genetic resolution allowed us to identify an allele associated with low BMD, which is different from the one found previously by other groups. Neither allelic heterogeneity of the VDR gene nor linkage disequilibrium of the VDR locus with another bone metabolism-related gene can be excluded to explain the differences in direction of the genetic effect between our study and other studies. Based on current evidence, it appears likely that the differences in bone mass between the different genotypes are obtained early in life rather than due to age-related bone loss. Studies of the association of VDR genotype with peak bone mass in younger individuals will help to clarify this issue.

\section{ACKNOWLEDGMENTS}

We thank Drs. J.A. Eisman and N.A. Morrison (Garvan Institute of Medical Research, Sydney, Australia) for primer information and helpful discussions, Dr. S.H. Ralston (University of Aberdeen, U.K.) for helpful discussions and communicating results prior to publication, Dr. C. van Broeckhoven (Antwerp University, Belgium) for providing some DNAs, and D. Algra and C.J. Buurman for technical assistance. This study was supported by the Dutch Praeventiefonds (grant \#002824890), by the NESTOR stimulation program for geriatric research in The Netherlands (Ministry of Health and Ministry of Education), the Municipality of Rotterdam, The Netherlands Organisation for Scientific Research (NWO), and the European Commision.

\section{REFERENCES}

1. Pocock NA, Eisman JA, Hopper JL, Yeates MG, Sambrook PN, Ebert S 1987 Genetic determinants of bone mass in adults: A twin study. J Clin Invest 80:706-710.

2. Christian JC, Yu PL, Slemenda CW, Johnston CC 1989 Heritability of bone mass: A longitudinal study in aging male twins. Am J Human Genet 44:429-433.

3. Morrison NA, Qi JC, Tokita A, Kelly PJ, Crofts L, Nguyen TV,
Sambrook PN, Eisman JA 1994 Prediction of bone density from vitamin D receptor alleles. Nature 367:284-287.

4. Spector TD, Keen RW, Arden NK, Morrison NA, Major PJ, Nguyen T, Kelly PJ, Baker JR, Sambrook PN, Lanchbury JS, Eisman JA 1995 Influence of vitamin D receptor genotype on bone density in postmenopausal women: A twin study in Britain. Br Med J 310:1357-1360.

5. Krall EA, Parry P, Lichter JB, Dawson-hughes B 1995 Vitamin D receptor alleles and rates of bone loss: Influence of years since menopause and calcium intake. J Bone Miner Res 10:978-984.

6. Riggs BL, Nguyen TV, Melton III LJ, Morrison NA, O'Fallon WM, Kelly PJ, Egan KS, Sambrook PN, Muhs JM, Eisman JA 1995 The contribution of vitamin D receptor gene alleles to the determination of bone mineral density in normal and osteoporotic women. J Bone Miner Res 10:991-996.

7. Yamagata Z, Miyamura T, Iijima S, Asaka A, Sasaki M, Kato J, Koizumi K 1994 Vitamin D receptor gene polymorphism and bone mineral density in healthy Japanese women. Lancet 344:1027.

8. Fleet JC, Harris SS, Wood RJ, Dawson-Hughes B 1995 The $B s m I$ vitamin $\mathrm{D}$ receptor restriction fragment length polymorphism (BB) predicts low bone density in premenopausal black and white women. J Bone Miner Res 10:985-990.

9. Melhus H, Kindmark A, Amer S, Wilen B, Lindh E, Ljunghall S 1994 Vitamin D receptor genotypes in osteoporosis. Lancet 344:949-950.

10. Hustmyer FG, Peacock M, Hui S, Johnston CC, Christian J 1994 Bone mineral density in relation to polymorphism at the vitamin D receptor gene locus. J Clin Invest 94:2130-2134.

11. Kröger H, Mahonen A, Ryhänen S, Turunen A-M, Alhava E, Mäenpää P 1995 Vitamin D receptor genotypes and bone mineral density. Lancet 345:1238.

12. Garnero P, Borel O, Sornay-Rendu E, Delmas PD 1995 Vitamin $D$ receptor gene polymorphisms do not predict bone turnover and bone mass in healthy premenopausal women. J Bone Miner Res 10:1283-1288.

13. Lander ES, Schork NJ 1994 Genetic dissection of complex traits. Science 265:2037-2048.

14. Hofman A, Grobbee DE, de Jong, PTVM, van den Ouweland FA 1991 Determinants of disease and disability in the elderly: The Rotterdam Elderly Study. Eur J Epidemiol 7:403-422.

15. Uitterlinden AG, Pols HAP, van Daele PLA, Algra D, Hofman A, Birkenhäger JC, van Leeuwen JPTM 1995 Vitamin D receptor genotype is associated with bone mineral density in humans (abstract 207). Calcif Tissue Int 56:419-512.

16. Uitterlinden AG, Pols HAP, van Daele PLA, Burger $H$, van Duijn CM, Hofman A, Birkenhäger JC, van Leeuwen JPTM 1995 Association between Vitamin D receptor gene polymorphisms and bone mineral density: Improved genetic resolution by direct haplotyping (abstract 90). J Bone Miner Res 10:S161.

17. Burger H, van Daele PLA, Algra D, van den Ouweland FA, Grobbee DE, Hofman A, van Kuijk C, Schutte HE, Birkenhager JC, Pols HAP 1994 The association between age and bone mineral density in men and women aged 55 years and over: The Rotterdam Study. Bone Miner 25:1-13,

18. Morrisson NA, Yeoman R, Kelly PJ, Eisman JA 1992 Contribution of transacting factor alleles to normal physiological variability: Vitamin D receptor gene polymorphisms and circulating osteocalcin. Proc Natl Acad Sci USA 89:6665-6669.

19. Hustmyer FG, Deluca HF, Peacock M 1993 ApaI, BsmI, EcoRV and TaqI polymorphisms at the human vitamin D receptor gene locus in Caucasians, Blacks and Asians. Hum Mol Genet 2:487.

20. Houston LA, Grant SFA, Reid DM, Ralston SH 1996 Vitamin $\mathrm{D}$ receptor polymorphism, bone mineral density, and osteopo- 
rotic vertebral fracture: studies in a UK population. Bone 18:249-252.

21. Matsuyama T, Ishii S, Tokita A, Yabuta K, Yamamori S, Morrison NA, Eisman JA 1995 Vitamin D receptor genotypes and bone mineral density. Lancet 345:1238-1239.

22. Heaney RP 1993 Nutritional factors in osteoporosis. Ann Rev Nutr 13:287-316.

23. Ferrari S, Rizolli R, Chevalley T, Slosman D, Eisman JA, Bonjour J-P 1995 Vitamin-D-receptor-gene polymorphisms and change in lumbar-spine bone mineral density. Lancet 345:423-424.

24. van Duijn CM, de Knijff P, Wehnert A, de Voecht J, Bronzova JB, Havekes LM, Hofman A, van Broeckhoven C 1995 The apolipoprotein $E \epsilon 2$ allele is associated with an increased risk of early-onset Alzheimer's disease and a reduced survival. Ann Neurol 37:605-610

Address reprint requests to:

Dr. A.G. Uitterlinden

Department of Internal Medicine III

$F G G-E U R$

Medical Faculty Erasmus University Rotterdam P.O. Box 1738

3000 DR Rotterdam, The Netherlands

Received in original form August 7, 1995; in revised form April 29, 1996; accepted May 8, 1996. 